\title{
Owning up to Uncertainty in Macroeconomics A Comment
}

\author{
by Manfred J. M. Neumann*
}

\begin{abstract}
George von Furstenberg and Jin-Ho Jeong have provided a wide-ranging survey of the treatment of uncertainty in macroeconomic reasoning since the late sixties, reminding us of many articles we have read in the past or should have read. Clearly, macroeconomics has fruitfully departed from the relatively quiet world of nonstochastic theory and progressed into an exciting and, possibly, disturbing variety of theoretical and empirical approaches, designed to further our understanding of how private agents as well as policy makers try to cope with uncertainty by producing, organizing, disseminating, and evaluating information. As a general observation, it appears hard to tell at this time which of the great many different strands of ideas and research programs have taken a promising direction and which will turn out to be blind alleys.
\end{abstract}

I shall restrict my comments to two of the issues surveyed by the authors: (1) How are the phenomena of inflation and relative price uncertainty related when agents suffer from a (local-global) confusion of contemporaneous shocks? (2) What may have been major lessons for policy makers had they followed the evolution of stochastic macroeconomic theory?

Before I address these issues let me briefly point out that in macroeconomic theory we deal with different scenarios of uncertainty, related to different time dimensions. The first scenario concentrates on the traditional and obvious concept of uncertainty about future events. The second scenario takes in addition uncertainty about contemporaneous events into account. For example, agents may sample today's prices for a small number of goods but they cannot observe today's general price level. The most complicated scenario, finally, arises when we permit uncertainty about past events to play a role. If, for example, the permanent component of monetary expansion is a random walk and the transitory component a white noise process we will even ex-post be unable to isolate precisely the permanent component in past observations. But note that in a less well known article Muth (1960) has developed an optimal prediction procedure which minimizes the permanent-transitory confusion.

\footnotetext{
* Professor at the University of Bonn.
} 
I now take up the first of the two issues seleeted for discussion : the relation between inflation and relative price variability. I think it is useful to differentiate between the concepts of the observed variance of relative prices, on the one hand, and relative price uncertainty, on the other. The observed variance of relative prices is clearly positively related to the unexpected (absolute) rate of inflation, i.e. the absolute forecast error. But this does not hold for the more interesting concept of the conditional variance which represents relative price uncertainty. Instead, by using a multimarkets equilibrium framework it can be shown that relative price uncertainty and inflation uncertainty are simultaneously determined by the variances of aggregate and relative shocks as perceived by agents; see Cukierman (1983). Rather than being determined by the level of inflation relative price risk can be modeled to be a determinant of inflation, on the grounds that it may negatively affect capacity output (Neumann and von Hagen, 1987).

With respect to the second issue - lessons to draw by policy makers - I think an early and important answer was given by Poole (1970). As the authors report, Poole showed that under uncertainty the optimal setting of policy instruments depends on the relative importance - in terms of second moments - of real sector shocks versus financial sector shocks, if the policy aim is to minimize the variance of output. In general, pure policies of interest rate or money stock control will be inferior to a combination policy, provided policy makers know the stochastic structure of the economy well enough to compute the optimal values of the money supply parameters.

Now in their paper the authors go through the exercise of complicating the stochastic structure of the Pool-model by introducing the money demand disturbances additionally into the aggregate demand function (p.77). Obviously, if this modification is justified, it will make it more difficult for the authorities to compute the optimal values of the policy parameters though the task will not become impossible, for given distributions of the exogenous shocks.

But Pool's analysis carried a useful message for those policy makers who have sufficient knowledge about the distributions of real and financial sector shocks but insufficient knowledge about the exact shapes of the structural equations. The message was that in order to stabilize production and employment the authorities should target a money stock measure rather than peg the interest rate of the exchange rate so long as real sector shocks are the dominant source of uncertainty in the economy. ${ }^{1}$

However, the Pool-analysis had a serious defect: it built on the assumption that private agents behaved as if they believed to live in a world of certainty. It required the advent of new classical macroeconomics to bring the conditioning role of private expectations formation and of uncertainty perception into focus. The new classicals changed the whole macroeconomic paradigm with far-reaching policy implications when they added a Lucas supply function to the basic model and postulated equilibrium rational expectations by private agents, i.e. the equality of subjective and objective conditional expectations.

A first obvious policy implication was that stabilization policies, directed at production and employment, are doomed to fail because rational agents who process and exploit all available information will accurately anticipate systematic action, hence transform by their

\footnotetext{
1 This message can be given precise analytical content for any specific structure.
} 
optimal decisions any intended real impact into an undesired pure price level affect. A second implication was that the real impact of unanticipatable policy surprises is inversely related to the degree of policy uncertainty as perceived by agents.

Policy makers may be inclined to conclude from these results that a new kind of combination policy is optimal where an announced and pursued path of permanently low. or zero inflation is supplemented from time to time by surprise deviations. This concept of timeinconsistent policy behavior implies to alternate between periods of accumulating credibility and periods of trading on it. However, recent application of game theory to such problems, reported on by von Furstenberg and Jeong, shows that no concept of planned time inconsistency provides a feasible equilibrium solution. Private agents will punish the authorities by shifting their expectations about the future policy course in an adverse manner. Hence optimizing authorities will secure reputation only, if they set the incentive-compatible or enforceable rate of inflation.

Unfortunately, when we look to the real world there is no government or central bank which foregoes time inconsistency. The enforcement mechanism visualized by game theorists apparently does not work sufficiently. This requires explanation.

To some extent, I think, it may result from expectational inertia and from uncertainty about the distributions, shaping the ongoing stochastic processes. When agents - watching and predicting the authorities - and the authorities - watching and predicting the predictions of the agents - are confronted with uncertainty about first and second moments, the game-theoretic concepts of an "enforceable inflation rate" or of the "punishment schema" loose force, in the sense that their empirical counterparts move with the perceptions of agents and of the authorities.

An alternative explanation of time inconsistency may be based on the conjecture that the authorities utility function changes frequently with the people in charge of policy decisions and their personal interests.

In any case, the survey by von Furstenberg and Jeong amply demonstrates that in order to adequately study these types of problems we will have to go beyond the rudimentary approaches developed so far. To paraphrase Hirshleifer (1970): stochastic macroeconomic theory is and will remain an unfinished story. 


\section{REFERENCES}

BARRO, R.J. and D.B. GORDON, 1983, "Rules, Discretion and Reputation in a Model of Monetary Policy", Journal of Monetary Economics 12, 101-121.

CUKIERMAN, A., 1983, "Relative Price Variability and Inflation: A Survey and Futher Results", in K. Brunner and A.H. Meltzer (eds.), Variability in Employment, Prices, and Money, CarnegieRochester Conference Series, vol. 9, Amsterdam: North Holland, 103-157.

HIRSHLEIFER, J., 1970, Investment, Interest, and Capital, Englewood Cliffs: Prentice Hall.

MUTH, J.F. 1960, "Optimal Properties of Exponentially Weighted Forecasts", Journal of the American Stastistical Association 55, 299-306.

NEUMANN, M.J.M and JÜRGEN VON HAGEN, 1987, "Relative Price Risk in an Open Economy with Flexible Exchange Rates", Discussion Paper no. A-97, Bonn, Sonderforschungsbereich 303.

POOLE, W., 1970 "Optimal Choice of Monetary Policy Instruments in a Simple Stochastic Macro Model”, Quarterly Journal of Economics, 84, 197-216. 